\title{
COVID-19 Outbreak Anxiety: Attitude and Preventive Actions of Filipino Teachers in Shaanxi, China
}

\author{
Saddam C. Bazer ${ }^{1}$ and Edison B. Estigoy ${ }^{2}$ \\ ${ }^{1}$ Shaanxi Normal University \\ ${ }^{2} X i$ 'an International Studies University \\ DOI: https://dx.doi.org/10.47772/IJRISS.2021.5401
}

\begin{abstract}
The novel-coronavirus disease is presently a global health threat and civic health emergency of worldwide concern. China is doing its best to control and implement measures necessitated by the current situation of COVID-19. Filipino Teachers in Shaanxi China are in no exemption in dealing with COVID-19 anxiety and other pressing challenges. Despite a better condition during the pandemic, Filipino teachers are still observing preventive actions related to COVID-19. An online survey was designed to collect the perceptions of the Filipino teachers in Shaanxi China about attitude and preventive actions in dealing with anxiety. Results showed that Filipino teachers foster a positive attitude in spite of the drastic changes in the community and even staying in China during and after postoutbreak. Further results revealed that preventive actions are being observed by the Filipino teachers when they are in public places to deal with COVID-19 anxiety even it's in the postoutbreak. Moreover, there was no gender divide established across the investigated variables. The study relied primarily on self-assessed experiences of Filipino teachersand future studies may involve a larger population, other nationalities and with comparison to the citizens as respondents.
\end{abstract}

Keywords: Attitude, Preventive Actions, Anxiety, Filipino Teachers, COVID-19, Shaanxi China

\section{INTRODUCTION}

A state of financial emergency and mental trouble hurriedly unfolded worldwide as an aftereffect of Covid disease 2019 (COVID-19) triggered by severe acute respiratory syndrome coronavirus 2 (SARS-CoV-2) disease in the Chinese city of Wuhan. Albeit social happenings have been delimited in many nations, practically all not-required individual activities were banished because of isolate, while the nearby clinics got quickly a large number of analytically sick COVID-19 patients and were obligatory to carry out their crisis protocols (Xiang et al., 2020). The infection has quickly spread across the limits to a few countries on the planet upsetting numerous individuals both youthful and old, making the spreading pandemic. This pandemic has controlled to a huge public reaction, with online media creating such a lot of awareness to keep individuals learned about the circumstance. Thakur and Jain (2020) asserted that the pandemic, with webbased media, is making a bit of worry for individuals going to some degree of intensified uneasiness and distressing response. The pandemic constrained a few measures by the nations to control the spread which joined securing of boundaries and limitations of human commitment and transport of superfluous products, closing down of spots of worship, and learning for a little while to months. The results have shifted from social effects on the economic affectation of people, families, and associations.

As indicated by Duan and Zhu (2020) there are numerous mental inconveniences and huge results regarding emotional well-being including pressure, nervousness, misery, disappointment, vulnerability during COVID-19 flare-up happened progressively. The mental responses to COVID-19 pandemic may contrast from a frenzy conduct or aggregate delirium (Barbisch et al., 2020) to broad sensations of sadness and distress which are related with negative results including self-destructive conduct (Zhai and Du, 2020). Rubin and Wessley (2020) added that fundamentally, other wellbeing measures might be undermined by strangely raised uneasiness. Given the unrivalled rate and mortality resulting from its high contagiousness, it is significant for residents to embrace proper preventive measures to defer and restrict the spread of this illness. In the U.S. furthermore, different nations, cultural measures (e.g., stay-at-home requests, travel limitations, and the conclusion of unimportant organizations and schools) have been executed (The Lancet, 2020).

At the individual level, it's basic to make preventive moves as defensive measures. As indicated by a few wellbeing conduct speculations, like the Health Belief Model (HBM) and the Theory of Planned Behavior (TPB) saw hazard is a major component in a people's commitment in preventive conduct (Ajzen, 1991). Seen hazard frequently envelops apparent defencelessness or an individual's impression of the danger of getting an infection and seen seriousness, one's view of the seriousness of the sickness. Both HBM and TPB suggest that people are probably going to carry on in manners that mitigate the peril of an illness when they see they are actually defenceless against a sickness and that impacts of contracting it would be serious (Janz and Becker, 1984; Rosenstock, Strecher, and Becker, 1988).

In the circumstance of COVID-19, people are bound to utilize preventive practices on the off chance that they see they are in danger (vulnerability and seriousness) from the Covid. Other 
conduct models, like the Planned Risk Information Seeking Model (PRISM) (Griffin, Dunwoody, and Neuwirth, 1999) and the Theory of Motivated Information Management (TMIM) (Afifi and Weiner, 2004), give extra knowledge. The PRISM and the TMIM approval that a person's apparent danger is interceded by the person's emotional danger reactions (e.g., tension and dread). Further, when individuals consider the danger of an infection to be grave and defenceless to its impact, they experience stress and dread connected with the danger. Such enthusiastic answers may trigger to acquire information to deal with the danger. With regards to COVID-19, when people feel uneasiness and dread related with the infection in the wake of seeing the danger of this infection, they may look for data to imperative their danger of getting the sickness.

As the number of coronavirus cases rise across the globe, the level of anxiety within the community is increasing. Feeling of worry and unease can be expected following a stressful event, such as the declaration of global pandemic Wang et al., (2020). Geographically, Shaanxi is just two (2) hours by plane from Wuhan and the number of infected cases in Shaanxi is not significantly different during the outbreak.The Filipino teachers in Shaanxi, China is not an exception to most effects, considering living and staying where everything started and concurrently far from family. Cognizant to the abovementioned concept, this study aims to seek the Filipinoteachers' attitude and preventive actions during the post-COVID-19 outbreak. Since most of the studies have been with their respective nationals, this study is unique to its respondents, Filipino teachers as foreigners and are staying in a country where COVID-19 outbreak started. This study is conceived to find out the attitudes and preventive actions of the respondents and the responses according to gender. While COVID-19 lingers to spread it is critical that communities expend actions to prevent supplementary transmission, decrease the effects of the outbreak and support constraint measures.

\section{Research Questions}

The following questions guided the development a direction of the present study:

1. What are the preventive actions and attitude of the respondents toward COVID-19 outbreak anxiety?

2. Is there a significant difference in the attitude and preventive actions between male and female respondents?

\section{LITERATURE REVIEW}

\section{Attitude toward pandemic}

Thinking about the worldwide point of view, in the Philippines, Filipino educators generally follow the public authority arrangements in managing uneasiness because of the COVID-19 outbreak. Their practices include looking for preventive measures, and other adapting intends to manage tension during the isolate stage. Aftereffects of the investigation uncovered that educators practice computercreated learning, associate with the expert society, submit to isolate necessities, and find deliberate endeavors to manage tension because of the suspension of public school-related exercises brought by the pandemic (Talidong and Toquero, 2020). The article set forward that there is adequate sign that the Filipino instructors practice measures to manage uneasiness since they submit to the preventive and instructive arrangements of the public authority; in this way, supporting the social trust among individuals and the public authority.

Furthermore, the study of Hager et al., (2020) gave the members' mentality towards COVID-19 was satisfactory. The majority of the respondents had an uplifting mentality towards defensive measures being told by the World Health Organization (WHO) or their neighborhood wellbeing specialists. Most respondents respected the significance of legitimate neatness, self-separation, the act of face covers when going out, and the ideal distance between two individuals in controlling the spread of the infection. Further, a portion of the respondents were exhausted, terrifying, and troubled to get back to the "new normal". In accordance with the upheld lockdown, which has psychosocially modified the way of life of most Nigerians and Egyptians, individuals have adjusted by following the online media stages and among different methods for evolving. Others felt idealistic and glad that all things considered, the world can lessen the effect or forestall the event of a comparable future pandemic. Hager et al., (2020) set forward that this disposition is empowering as it would encourage inevitable control of the pandemic. Thusly, raised that the public authority needs to support its wellbeing frameworks, and grow its reconnaissance exercises, to have the option to surmised and distinguish cases, contact following, appropriately disengage contaminated patients and effectively apply standard disease avoidance and control measures.

Paudel et al., (2020) raised that the majority of the respondents concurred that COVID-19 will totally be effectively controlled and this attitude was fundamentally extraordinary across genders and home regions. About $80 \%$ of the members had certainty that Nepal can win the fight against COVID-19. Be that as it may, none of the socio-segment qualities were found to be identified with the certainty of winning the fight against the sickness. Out of the all-out members, the dominant part had not visited any packed spot and destroyed covers while going as of late. The act of heading for a packed spot fundamentally contrasted across segment qualities and on the other hand, the act of wearing a cover while going outside essentially varied distinctly across sex. The investigation closed to have a necessity to convey training and mindfulness about COVID-19 to Nepalese focusing on the knowledge gap so Nepal can have triumph against COVID-19.

Mosaddek et al., (2020) showed that more ideal information is identified with more uplifting perspectives and more rehashed rehearses towards COVID-19 yet unimportant. 
Notwithstanding, the proportion of more precise information, more positive attitudes, and more successive practices was not momentous, suggesting that powerful wellbeing training plans proposed at improving COVID-19 information, which builds more inspirational mentalities and being careful supported practices. For each question of attitude, the circulation of reactions from members with genders contrasts shifts. The reaction paces of "Agree" were fundamentally higher in females to the thing of mentality segment concerning "It is crucial to report a suspected case to health authorities". Besides, the reaction rates of "Agree" were altogether higher in females to the thing of mentality area in regards to "It is important to use a face mask in a crowded place." The discoveries indicated that $55.2 \%$ of respondents had more regular practices, and $44.8 \%$ of respondents had similarly less frequent practices towards the COVID-19. The examination battled to improve the information, mentalities, and practices of all-inclusive communities is basic during the rushed ascent phase of the COVID-19 episode. Consequently, an operational wellbeing training program should be started.

The current study of Alwani et al., (2020) exhibited an uplifting disposition of the medical caretakers towards COVID-19. Medical attendants (96\%) who have devoted themselves to COVID-19 patients will proceed with their work. An enormous number of medical caretakers (92.3\%) need more individuals to be prepared to battle with COVID19 and $(75.6 \%)$ of the medical caretakers don't need more orderlies with the patients in the emergency clinic. The examination reasoned that the attendants completing their obligations with COVID-19 positive patients have great information and disposition. However, their nervousness levels are high; consequently, the investigation proposed having mental associations sideways with bits of preparing ought to be given.

\section{Preventive Actions during Pandemic}

In the investigation of Hager et al., (2020) the disposition of most respondents towards set up preventive measures was good with a average attitude. Most of the respondents practiced self-disengagement and social-separating in any case just $36 \%$ follow all wellbeing proposals. The impression of most respondents on the worldwide endeavors at controlling the infection and forestalling additionally spread was agreeable with a normal score and just $22 \%$ of the respondents were happy with their nation's treatment of the pandemic.

Wong et al., (2020) contended a summation of reactions comparative with the implementation of preventive measures during the Past Week (PW) and beginning of the outbreak (BO) periods. All through the PW time frame, the most elevated extent of utilization of individual defensive measures was for respondents who often washed their hands with cleanser, trailed by the individuals who wore a cover. Concerning cough etiquette, the most much of the time practice preventive measures were discarding tissues promptly and covering one's mouth and nose when hacking or wheezing. Continually performing hand cleanliness was accounted for by a high extent of the members. Over 33\% of respondents related that they generally dodged closeness with others and avoided assembling in gatherings. Almost $66 \%$ announced that they continually isolated themselves deliberately in the event that they were feeling ailing, however less than half said they would consistently report instantly to wellbeing specialists on the off chance that they were feeling unwell. The investigation reasoned that nervousness and preventive estimates scores were high and expanded with the pandemic rate. Higher nervousness was associated with expanded utilization of preventive measures against COVID-19.

\section{COVID-19 anxiety}

Disease outbreaks, for example, the COVID-19 pandemic are anxiety-provoking circumstances. Spielberger (2010) characterized nervousness as a 'condition of anxiety or worry coming about because of the expectation of a genuine or perceived compromising occasion or circumstance. Tension is common among medical services work force who are straightforwardly occupied with taking care of influenced patients during pandemics. Further, because of their immediate contact with COVID-19 patients, medical care laborers (HCWs) are more presented to horrendous accidents like patients' affliction and passings (Pappa et al., 2020), which may be added or enhance their feelings of dread and nervousness. Accessible information proposes that the predominance of tension among HCWs during pandemic went from $22.6 \%$ to $36.3 \%$ (Liu, Gayle, Wilder-Smith, and Rocklöv, 2020), and these rates were altogether higher than those observed in the general population. Among HCWs, medical caretakers were portrayed to encounter the most elevated nervousness levels and the most noteworthy predominance of tension, going from $15 \%$ to $92 \%$ (Alwani et al., 2020; Luo, Guo, Yu, and Wang, 2020).

Mohammadpour et al., (2020) asserted in the cross-sectional investigation, 403 individuals reacted online inquiries on the Generalized Anxiety Disorder 7-Item (GAD-7) Scale, SelfCompassion Scale (SCS), Fear of COVID-19 Scale (FCV19S), and a poll zeroing in on COVID-19-related conduct. Results uncovered that there was a critical connection between friendly distance and sexual orientation, and individuals who noticed social removing passed on more significant levels of dread of COVID-19. No critical relationship was found between handwashing conduct and sexual orientation factors, conjugal status, and schooling. There was a huge contrast between the individuals who addressed yes to self-care practices identified with washing and the individuals who addressed no as far as factors of fear of COVID-19, the general score of empathy, and subscales of sympathy, including self-generosity and segregation. Comparable to fear of COVID-19, hitched status, tension, and normal mankind had a positive relationship with dread of COVID-19. Nonetheless, self-judgment was contrarily identified with fear of COVID-19. As per the discoveries of 
the examination, men and individuals who are less terrified of COVID-19 are more probable not to notice self-care practices. The examination commented that giving preparing concerning treatment conventions is fundamental for these individuals. Suggestion expressed that to decrease the fear of the sickness in individuals with significant degrees of fear, clinicians, therapists, and other clinical staff can utilize conventions to expand empathy.

About the fear of COVID-19, the factors of marital status, nervousness, and the part of basic humankind emphatically connected with the degree of dread of COVID-19 (Usher et al., 2020). Then again, the segment of self-judgment was adversely identified with this fear. The discoveries clarified that it very well may be expressed during this time, individuals' vulnerabilities normally increment, and meanwhile, individuals are more uncertain about the end results of isolate on the wellbeing and instructive status of their relatives. Additionally, on the grounds that this infection has spread worldwide and individuals are presented to a typical infection and have not yet had the option to discover an antibody, it has caused an overall fear of the illness. Individuals showed more negative feelings (nervousness, misery, and outrage) and more negative feelings after COVID-19 was reported as a pandemic by the World Health Organization (WHO). Hence, fear and uneasiness assume a practical part in the present circumstance.In the study of Talidong and Estigoy (2020) respondents are Foreign teachers who are facing the common difficulties the world is confronting. The respondents are more helpless in anxiety since the pandemic is as yet continuous and with regards to Foreign educators in Xi'an China, they are far away from family and are living in foreign land.

The applicable writing and studies introduced data and exact information on the nervousness or fear brought by the pandemic and the various reactions, responses, and attitudes of the respondents as they face COVID-19. It additionally gives information on the distinctive preventive estimates set by various associations and on how individuals are reacting to various preventive activities set forth by the local area and state. There is a gap in information concerning the respondents' (Filipino instructors) reactions as outsiders or living outside their individual nations while confronting the problems brought by the COVID-19 flare-up and on-going pandemic. It is along this line where this investigation endeavored to fill in the gap and to add to growing the outskirts of information. Furthermore, the investigation looks to help or differentiation the current discoveries of attitude and preventive activities across gender.

\section{METHODOLOGY}

\section{Research Design}

The current investigation employed a quantitative-descriptive design. The study is noted to be quantitative as it intended to appraise or measure the variables accounted in this current research (Kothari, 2004). In addition, the study is considered descriptive as it aimed to investigate the immediate status of a phenomenon or phenomena (Singh, 2006), relevant to the study which supported the objective of identifying the respondents' attitude and preventive actions during the postCOVID-19 outbreak and ongoing pandemic. Moreover, the study involved the processes of data collection, tabulation, analysis and description which further justify its being a descriptive type of research (Calderon, 2006 cited in Rillo \& Alieto, 2018; Dealagdon, et. al., 2020). In addition, the study is noted to be population-based as it is directed towards specific members of a population (Buslon \& Alieto, 2019; Estigoy \& Sulasula, 2020).

\section{Respondents}

An unidentified online population-based survey was acted upon. In general, the study samples a total of fifty (50) Filipino teachers who are currently in Shaanxi, China. In terms of gender, females $(64 \%)$ and males $(36 \%)$ respondent.

\section{Research Instrument}

For the purposes of this study, a questionnaire was devised to gather data.The items of the researcher-made questionnairechecklist were carefully constructed based on existing literature. Specifically, the items were founded from the previous study of Talidong and Toquero, (2020). Revisions of the statements were made to fit the objectives of the study. To ensure relevance and accuracy of the instrument, it was subjected to validation. The research instrument was referred to colleagues and experts and made further improvement. All suggestions and corrections were incorporated. Items found to be not relevant were omitted from the instrument and the items found ambiguous were revised according to the suggestions.

\section{Validity and Reliability}

The survey questionnaire was constructed based on the research literature and problems of the study. As to the validity of the instrument, the prepared survey questionnaire was submitted to an expert who independently validated its content in terms of relevance, suitability and appropriateness to the research problems, after consolidating the suggestions given by the experts, the research instrument was subjected for reliability testing. The researchers made sure that the participants are unaware of the desired outcome of the study, this is to ensure the most accurate data will be acquired. For the attitude and preventive actions as variables, the research focus on the attitude of the participants toward COVID-19 anxiety and the different preventive actions implemented.For the reliability testing of the research instrument, the questionnaire was subjected to pilot testing. The researcher administered to selected foreign teachersand the data were then subjected to Cronbach Alpha and a coefficient of 0.85 was obtained which is interpreted as "Good". Hence the instrument is considered reliable for the purpose of answering the problems of this study. 


\section{Data Collection and Coding Procedure}

An online survey with 14 statements was designed to collect the perceptions of the Filipino teachers in Shaanxi China relevant to the aspect of preventive actions ( 7 items) and attitudes (7 items) toward COVID-19 anxiety. These Filipino teachers were approached through an online platform specifically QQdocs, a survey tool conveniently available, and the generated link was distributedusing WeChat, the most popular social media app.The link was also shared personally to the contact list of researchers. They were requested to participate voluntarily in the study. A pilot test was done with fifteen foreign teachers before the final conduct of the online survey. The online survey was done for the duration of one week (October 5 to October 12, 2020) during the postCOVID-19 outbreak. The gathered data from the research tools were coded to enable analysis through SPSS. Furthermore, fifty responses were analyzed using descriptive statistics specifically the mean percentage. The results were described using an adapted 5-point Likert scale presented below: 4.5-5.00Strongly Agree (5), 3.5-4.49Agree (4), 2.53.49Uncertain (3), 1.5-2.49Disagree (2), 1.0-1.49Strongly Disagree (1).

Ethical practices were carefully observed in the conduct of the study. There is no conflict of interest and the researchers are not inclined to influence the results of the study. Moreover, privacy and confidentiality of participant's information and responses were ensured and protected. The research did not involve vulnerable study population since respondents are adult professionals working in different organizations and places. The said respondents are competent to grant assent. The participation is completely voluntary and no form of renumeration for involvement in the study is expected. The study was approached through an online platform and that the respondents may answer in their most convenient time. The researchers also ensure that participants can refuse to answer certain questions or items, discuss certain topics or even refuse to answer the questionnaire without prejudice. Additionally, the researchers guarantee that the respondent can access the results of the study and have the right to access the data upon request.

\section{RESULTS AND DISCUSSION}

Filipino Teachers' preventive actions and attitude toward COVID-19 outbreak anxiety

The responses of the respondents on the questionnaires were all tabulated first in a spreadsheet. Afterwards, the raw data were transferred to SPSS for a descriptive analysis. Table 1.0 provides the analysis, it includes mean score (M), standard deviation (SD), and interpretation.

Table 1.0: Filipino Teachers' Preventive Actions and Attitude toward Covid19 Outbreak Anxiety

\begin{tabular}{|c|c|c|c|}
\hline Variables & Mean & SD & Interpretation \\
\hline Attitude & 4.13 & .385 & Agree \\
\hline Preventive actions & 4.18 & .361 & Agree \\
\hline
\end{tabular}

Thinking positively can help alleviate anxiety amid the global crisis (WHO, 2020). Based on the grand mean of 4.13 reveals that the Filipino teachers as a whole agree on the statements regarding attitude. As self-assessed by the teacher respondents, they strongly agree in the "importance of strictly following the preventive measures of the government to combat COVID-19, $(\mathrm{M}=4.62)$ " and to the statement "I believe my life will be back to normal soon (4.55)". This shows that foreign teachers in Shaanxi China have positive attitude in facing COVID-19 outbreak. Respondents feel that the association is accomplished toward them, for instance, implementing highperformance practices will overall react with inspiring points of view toward the association, including incredible bonds and impressions of steadfastness (Estigoy, et. al., 2020).Hence, decreasing the anxiety of the predicament brought by the pandemic (Kebede et al., 2020). To further support the positive attitude of Filipino teachers, responses under agree shows that Filipino teachers "feel positive for staying in China during the COVID-19 outbreak ( $\mathrm{M}=4.31)$ ", respondents "trust the news and updates about pandemic $(M=3.79)$ ", teachers "believe that life will be back to normal soon $(M=4.24)$," and that their "lifestyle changed because of COVID-19 outbreak $(\mathrm{M}=4.07)$ ". The above statements support the theory of PRISM and TMIM that when individuals feel anxiety and fear associated with the virus, response would likely to seek information. However, there is an exception to the general impression to the attitude of Filipino teachers amidst pandemic. The exception based on the weighted mean computed to have the least, which is "I feel secured using public transportation $(\mathrm{M}=3.31)$." As assessed by the respondents, they are still undecided in the security to use public transportation like bus, subway, fast train, and plane. These uncertainties are upshot of the COVID-19 preventive measures (Talidong \& Toquero, 2020). The result supports the study of Hager et al., (2020) that most respondents value the importance of using facial mask when going out and ideal distance between people. In addition, the study of Paudel et al., (2020) indicated that participants had not visited crowded place as part of preventive measures.Public transportations in China are considered to be one of the crowded places considering the number its of population.

Moreover, the preventive actions of Filipino teachers in dealing with anxiety of COVID-19 resulted to an overall mean of $(M=4.18)$ with a verbal interpretation of agree. It can be gleaned from the Filipino teachers' responses that they strongly agree that "social distancing as suggested by the government is important $(\mathrm{M}=4.52)$. In like manner, WilderSmith and Freedman (2020) concluded that social distancing helps to decrease the transmission of the infection. Social distancing is necessary for avoiding transmission of COVID19 , in spite of the fact that it prompts a sensation of trouble and tension among individuals. Further, there are five items under preventive actions with agree responses as they face and behave in the public. Talking to some acquaintances with mask on is being responsible $(\mathrm{M}=3.76)$ and a feeling of safe and confidence in public places $(M=4.48)$. This support the 
findings in the study of Wong et al., (2020) respondents preventive measures were to wash their hands with soap and wear mask. In addition, respondents agree in the statements "being conscious in touching any surface in public areas, as well as touching the face without washing hands in public garnered the same mean of 4.45 , and that disinfecting things before entering the house is necessary preventive actions $(\mathrm{M}=4.31)$ in dealing with COVID-19 anxiety. However, there is an exclusion to the general impression to the positive attitude of Filipino teachers amidst pandemic. The exclusion based on the weighted mean computed to have the least, which is "spending some time with friends like watching movies at malls is fine $(\mathrm{M}=3.24)$." As assessed by the respondents, they are still undecided in spending time and hanging out with friends like watching movies at malls. Respondents are undecided that it is fine to go out with friends in public places like movie house at malls. The authors (Roy et al., 2020 and Yang et al., 2020) put forward that it is basic for individuals to be receptive to the preventive measures to evade transmission of COVID-19 via noticing individual cleanliness, utilizing sanitizers, washing hands, and wearing veils. This additionally incorporates self-disengaging, rehearsing social separating, and drinking a lot of water.

\section{Attitude and Preventive Actions across Gender}

The raw data were computed and analyzed. To determine whether there is a significant difference in the attitude and preventive actions of the respondents when data are grouped according to gender, the inferential statistics known as T-test for independent sample was utilized. Presented in table 2.0 is the analysis.

Table 2.0: Attitude and Preventive Actions between Male and Female Respondents.

\begin{tabular}{|c|c|c|c|c|c|}
\hline Dependent & Independent & Mean & SD & $\begin{array}{c}\mathrm{p}- \\
\text { value }\end{array}$ & Interpretation \\
\hline \multirow{2}{*}{ Attitude } & Male & 4.22 & .21 & \multirow{2}{*}{.248} & \multirow{4}{*}{$\begin{array}{c}\text { Not } \\
\text { Significant }\end{array}$} \\
\hline & Female & 4.08 & .45 & & \\
\hline \multirow{2}{*}{$\begin{array}{l}\text { Preventive } \\
\text { Actions }\end{array}$} & Male & 4.10 & .36 & \multirow{2}{*}{.218} & \\
\hline & Female & 4.24 & .36 & & \\
\hline
\end{tabular}

$\mathrm{N}=50$ (20 Males and 30 Females)

Data in Table 2.0 reveals that the Filipino teachers' attitude and preventive actions are treated for significant difference when grouped by gender, the T-test analysis shows that the probability value at .248 and .218 respectively which are greater than alpha 0.05 .

This implies that there is no significant difference between the male and female respondents across variables. Therefore, gender does not significantly affect teachers' attitude and preventive actions toward COVID-19 outbreak anxiety and does not differ regardless of gender. This further implies that whatever the gender of the teacher, their attitude and preventive actions toward COVID-19 outbreak anxiety do not significantly differ. Regardless of gender, Filipino teachers have positive attitude and that they equally observe preventive actions toward COVID-19 outbreak anxiety.

As per Addati et al., 2018 by and large, women have given on normal 3.3 occasions more consideration than men at home and from the investigation of Paudel et al., 2020 raised a huge contrast as indicated by genders when members agree in the attitude that COVID-19 will at long last be effectively controlled and to the acts of going to swarmed places and wearing a cover while outside. Adding to huge distinction across sexual orientation, in the investigation of Mosaddek et al., (2020) shows high critical rate in females' mentality. Thus, women are in danger of addressing a greater expense during the Covid-19 emergency than men because of the gigantic physical and mental responsibility they should take on (Blaskó and Papadimitriou, 2020; Wenham, Smith, Morgan, and Group, 2020). A few examinations have effectively written about the contrasts among people according to the mental effect of the pandemic and the presence of indications of nervousness and sorrow (González-Sanguino et al., 2020; Özdin and BayrakÖzdin, 2020; Wang et al., 2020a, 2020b; Zhang and Ma, 2020). Concerning the isolation of people, couple of studies that have been led demonstrate that there is a solid connection between being a woman and encounters of depression during the Covid-19 emergency (Losada-Baltar et al., 2020). All things considered, the current consequence of this investigation discredits the above discoveries and it shows no huge distinction in the disposition and preventive activities of the respondents across gender.

\section{CONCLUSIONS AND IMPLICATIONS}

There are a lot of factors involve that will result in a different attitude of the people in dealing with COVID-19. The respondents are more vulnerable in anxieties since the pandemic is still ongoing and in the context of Filipino teachers in Shaanxi China, they are far from family and is living in a foreign country, their lifestyles have been greatly affected and they reinforce the importance of preventive action to observe social distancing in public places. Filipino teachers in Shaanxi China have shown a positive attitude in life amidst the COVID-19 outbreak. Teachers though are equipped with what to do to adjust and cope with any possible anxieties. Therefore, this article points out that there are sufficient pieces of evidence that Filipino teachers observe preventive actions in public places and they have a positive attitude in dealing with pandemic anxiety in Shaanxi, China. However, this study has its limitations such as it cannot be generalized to the entire Filipino teachers nor to foreigners in China due to the limited number of teachers who answered and no means of reaching the entire population, and this study primarily relied on self-assessed experiences of the teachers. Nonetheless, the study presents social implications that the Filipino teachers remain to have a positive attitude in dealing with COVID-19 anxiety in spite of being far from family and not in the home country. Further, the study implies that Filipino teachers observe preventive actions in public places and as support to the government policies and regulations to 
control the spread of COVID-19. The pandemic knows no nationality nor status, it has affected everyone and people are adjusting continuously in the present situation. The study implies that regardless of the current location or in any foreign land, it is uplifting to know that attitude and compliance to preventive actions are being observed. Moreover, there is no significant difference in the attitude and preventive actions of respondents between males and females, that irrespective of gender, the fair responsibility is shared as support to the theory of planned behavior and health belief model that individuals will perform ways that mitigate the threat or risk. Further studies are encouraged to be conducted concerning the study with a larger scope of population, including the population of other nationals and other specific factors like social capital in dealing with COVID-19 anxiety and with respect to demography variables.

\section{REFERENCES}

[1] Addati, L., Cattaneo, U., Esquivel, V., \&Valarino, I. (2018). Care work and care jobs for thefuture of decent work. Available at: https://www. ilo. org/wcmsp5/groups/public/dgreports/dcomm/publ/documents/publication/wcms_633135.pdf

[2] Afifi, W., \& Weiner, J. (2004). Toward a theory of motivated information management.Communication Theory, 14, 167-190.

[3] Ajzen, I. (1991). The theory of planned behavior. Organizational Behavior and HumanDecision Processes, 50, 179-211.

[4] AlwaniSS, Majeed MM , Hirwani MZ, Rauf S, Saad SM , Shah H , Hamirani F (2020)Evaluation of Knowledge, Practices, Attitude and Anxiety of Pakistan's Nursestowards COVID-19 during the Current Outbreak in Pakistan.medRxiv preprint doi:https://doi.org/10.1101/2020.06.05.20123703

[5] Barbisch D, Koenig KL, Shih FY. (2015) Is there a case for quarantine? Perspectives from toEbola. Disaster Med Public Health Prep 2015; 9:547-53.

[6] Blaskó, Z., Papadimitriou, E., Manca, A.R. (2020). How will the COVID-19 crisis affectexisting gender divides in Europe? Luxembourg: Publications Office of the EuropeanUnion

[7] Buslon, J., \&Alieto, E. (2019). Lexical inferencing strategies and reading comprehension inEnglish: A case of ESL third graders. Asian EFL, 22(1), 73-94.

[8] Calderon, J. (2006). Methods of research and thesis writing (2nd $E d$.). Mandaluyong City:National Bookstore. In Alieto, E., \&Rillo, R. (2018). Language attitudes of Englishlanguage teachers (ELTS) towards Philippine English. Dimension Journal of Humanities and Social Sciences, 13(1), 84-110.

[9] Dealagdon, T., Teves, N., Tanpoco, M. and Estigoy, E., 2020. Reading and writing in the 21st Century: An Analysis of Preferences among Pre-service Language Teachers. Asian EFL Journal, 27(5.1), pp.5-30.

[10] Duan L, and Zhu G (2020). Psychological interventions for people affected by the COVID-19epidemic.Lancet Psychiatry 2020; 7: $300-2$.

[11] Estigoy, E., Bazer, S., Jimenez, J., Pineda, J., Zabala, S., 2020. High-Performance Work Practices: Extent of Implementation and Commitment in Higher Education Institutions. International Journal of Research and Innovation in Social Science, 05(01), pp.545-553. doi:10.47772/ijriss.2021.5126.

[12] Estigoy, E. and Sulasula, J., 2020. Factors Affecting Employee Commitment in the Workplace: An Analysis. Journal of Education and Practice, 11(27), pp.160-171

[13] González-Sanguino, C., Ausín, B., ÁngelCastellanos, M., Saiz, J., López-Gómez, A., Ugidos,C., \&Muñoz, M. (2020). Mental Health Consequences during the Initial Stage of the2020 Coronavirus Pandemic (COVID-19) in Spain. Brain, Behavior, and Immunity, $87,172-176$
[14] Griffin, R., Dunwoody, S., \& Neuwirth, K. (1999). Proposed model of the relationship of riskinformation seeking and processing to the development of preventive behaviors.Environmental Research, 80, 230-245.

[15] Hager E, Odetokun IA, Bolarinwa O, Zainab A, Okechukwu O, AlMustapha AI (2020)Knowledge, attitude, and perceptions towards the 2019 Coronavirus Pandemic: A binational survey in Africa. PLoS ONE 15(7): https://doi.org/10.1371/journal.pone.0236918

[16] Janz NK, Becker MH (1984). The health belief model: a decade later. Health Educ Q. 1984;11:1-47.

[17] Karen Joy B. Talidong\& Cathy Mae D. Toquero (2020) Philippine Teachers' Practices to Dealwith Anxiety amid COVID-19, Journal of Loss and Trauma, 25:67, 573579, DOI: 10.1080/15325024.2020.1759225

[18] Kebede Y, Yitayih Y, Birhanu Z, Mekonen S, Ambelu A (2020) Knowledge, perceptions andpreventive practices towards COVID19 early in the outbreak among Jimma universitymedical center visitors, Southwest Ethiopia. PLoS ONE 15(5): e0233744.https://doi.org/10.1371/journal.pone.0233744

[19] Kothari, C. (2004). Research Methodology (Second Revised Edition). New Delhi: New AgeInternational Publisher.

[20] Li Ping Wong, Chia-Chun Hung, Haridah Alias and Tony SzuHsien Lee (2020). Anxietysymptomsand preventive measures during the COVID-19 outbreak in Taiwan. BMCPsychiatry(2020) 20:376 https://doi.org/10.1186/s12888-020-02786-8

[21] Liu, Y., Gayle, A. A., Wilder-Smith, A., \& Rocklöv, J. (2020). The reproductive number ofCOVID-19 is higher compared to SARS coronavirus. Journal of TravelMedicine, 27(2), 1-4.

[22] Losada-Baltar, A., Jiménez-Gonzalo, L., Gallego-Alberto, L., Pedroso-Chaparro, M. D. S.,Fernandes-Pires, J., \& MárquezGonzález, M. (2020). "We're staying at home".Association of selfperceptions of aging, personal and family resources and lonelinesswith psychological distress during the lock-down period of COVID-19. The Journalsof Gerontology. Series B, Psychological Sciences andSocial Sciences.doi:10.1093/geronb/gbaa048

[23] Luo, M., Guo, L., Yu, M., \& Wang, H. (2020). The Psychological and Mental Impact ofCoronavirus Disease 2019 (COVID-19) on medical staff and general public-Asystematic review and meta-analysis. Psychiatry Research, 291, 113190.

[24] Mohammadpour M, Ghorbani V, Khoramnia S, et al. Anxiety, Self-Compassion, GenderDifferences and COVID-19 (2020): Predicting Self-Care Behaviors and Fear ofCOVID-19Based on Anxiety and Self-Compassion with an Emphasis on Gender DifferencesIranian Journal of Psychiatry. 2020 Jul;15(3):213-219.

[25] Mosaddek, J. A. Zegarra-Valdivia, Md. Tajuddin Sikder, Abu Syed Md.,Most. ZannatulFerdous, Md. Saiful Islam (2020) Knowledge, attitude, and practice regarding COVID-19 outbreak in Bangladeshi people: An online-based cross-sectional study. medRxiv preprint doi: https://doi.org/10.1101/2020.05.26.20105700

[26] Özdin, S., \& BayrakÖzdin, Ş. (2020). Levels and predictors of anxiety, depression and healthanxiety during COVID-19 pandemic in Turkish society: The importance of gender.International Journal of Social Psychiatry, 0020764020927051.10.1177/0020764020927051

[27] Pappa, S., Ntella, V., Giannakas, T., Giannakoulis, V. G., Papoutsi, E., \& Katsaounou,P. (2020). Prevalence of depression, anxiety, and insomnia among healthcare workersduring the COVID-19 pandemic: A systematic review and meta-analysis. Brain, Behavior,

and Immunity, 88, 901- 907. https://doi.org/10.1016/j.bbi.2020.05.026

[28] PaudelSachina, Shrestha Prabin, KarmacharyaIsha, and Pathak Om Krishna (2020)Knowledge, attitude, and practices (KAP) regarding COVID-19 among Napaleseresidents during the outbreak: An online cross-sectional study. Research Squarepreprint doi: https://doi.org/10.21203/rs/3/rs-31044/v1 
[29] Rosenstock IM, StrecherVJ, BeckerMH (1988).Sociallearningtheoryandthehealthbelief model.Health Educ Q. 1988; $15: 175-183$.

[30] Rubin GJ, Wessely S. (2020) Coronavirus: the psychological effects of quarantining a city.BMJOpinion 2020; 368:m313.

[31] Singh, Y. (2006). Fundamental of Research Methodology and Statistics. New Delhi: NewAge International.

[32] Spielberger, C. D. (2010). State-Trait anxiety inventory. The Corsini Encyclopedia ofPsychology. Hoboken, NJ: John Wiley \& Sons, Inc. Google Scholar.

[33] Talidong, K. and Estigoy, E., 2020. Social Trust of Foreign Teachers amidst Covid-19 Anxietyin Xi'an, China. International Journal of Research and Innovation in Social Science,04(12), pp.246-350.

[34] Thakur V, Jain A. (2020) COVID 2019-suicides: A global psychological pandemic. BrainBehav Immun. 2020 Aug;88:952-953. doi: 10.1016/j.bbi.2020.04.062. Epub 2020 Apr23.PMID: 32335196; PMCID: PMC7177120.

[35] The Lancet Respiratory Medicine (2020). COVID-19: delay, mitigate, and communicate.Lancet Respir Med. 2020;8:321. https://doi.org/10.1016/S2213-2600(20)30128-4.

[36] Usher, K., Bhullar, N., Durkin, J., Gyamfi, N., \& Jackson, D. (2020). Family violence andCOVID-19: Increased vulnerability and reduced options for support. International Journal of Mental Health Nursing, 29(4), 549-552.

[37] Wang C, Horby PW, Hayden FG, (2020). A novel coronavirus outbreak of global healthconcern. Lancet 2020; 395(10223):470 73. [published Online First: 2020/01/28]https://doi.org/10.1016/S0140-6736 (20)30185-9 PMID: 31986257

[38] Wang, C., Pan, R., Wan, X., Tan, Y., Xu, L., Ho, C. S., \& Ho, R. C. (2020a). Immediatepsychological responses and associated factors during the initial stage of the 2019coronavirus disease (COVID-19) Epidemic among the General Population in China.
International Journal of Environmental Research and Public Health, 17(5), 1729

[39] Wang, C., Pan, R., Wan, X., Tan, Y., Xu, L., McIntyre, R. S., . . Ho, C. (2020b). A longitudinalstudy on the mental health of general population during the COVID-19 epidemic inChina. Brain, Behavior, and Immunity, 87, 40-48.

[40] Wenham, C., Smith, J., Morgan, R., \& Group, G. (2020). COVID19: The gendered impactsof the outbreak. Lancet, 395 (10227), 846-848.

[41] Wilder-Smith, A., \& Freedman, D. O. (2020). Isolation, quarantine, social distancing andcommunity containment: Pivotal role for oldstyle public health measures in the novelcoronavirus $(2019-\mathrm{nCoV})$ outbreak. Journal of Travel Medicine, 27(2), 1-4. https://doi.org/10.1093/jtm/taaa020

[42] World Health Organization. (2020, March 18). Mental health and psychosocial considerationsduring the COVID-19 outbreak. https://www.who.int/docs/default-source/coronaviruse/mentalhealth-considerations.pdf

[43] Xiang YT, Yang Y, Li W, Zhang L, Zhang Q, Cheung T, et al. (2020) Timely mental healthcare forthe 2019 novel Coronavirus outbreak is urgently needed. Lancet Psychiatry2020;7:228-9.

[44] Yang, H., Bin, P., \& He, A. J. (2020). Opinions from the epicenter: An online survey ofuniversity students in Wuhan amidst the COVID-19 outbreak1. Journal of ChineseGovernance, 1-15. https://doi.org/10.1080/23812346.2020.1745411

[45] Zhai Y, Du X. (2020) Loss and grief amidst COVID-19: a path to adaptation and resilience.Brain BehaviorImmun 2020; S0889-1591: 30632.

[46] Zhang, Y., \& Ma, F. Z. (2020). Impact of the COVID-19 pandemic on mental health and qualityof life among local residents in Liaoning province, China: A cross-sectional study. InInternational Journal of Environmental Research and Public Health, 17(7).doi:10.3390/ijerph17072381 